\title{
Survey on Specialty Identity of Community Management and Service in Vocational Colleges
}

\author{
Jun Mo * 1,2 and Ning Zhu \\ 1. School of Business, Hohai University, Nanjing211100, Jiangsu, China \\ 2. Wuxi Vocational College of Science and Technology, Wuxi214028, Jiangsu, China \\ * Corresponding Author (48587728@qq.com)
}

\begin{abstract}
Keywords: Vocational College; Community Management and Service; Specialty Identity; Promotion Strategy
\end{abstract}

\begin{abstract}
In view of the learning situation and obstacles of students in community management and service specialty of vocational colleges, this study uses survey questionnaires to investigate the students of this specialty. It is found that the students' low specialty identify results in poor learning situation and they are confused about employment and further intentions. This paper discusses the promotion strategies of specialty identity.
\end{abstract}

\section{Introduction}

The community management and service specialty is an emerging specialty since the $21^{\text {st }}$ century. It focuses on cultivating higher technical application specialists with basic theoretical knowledge and skills for community management and service work, which can adapt to the needs of China's social security and social welfare systems, urban community development, community management and service, property management and other social organizations and communities (Chen Zengrong, 2008; Wang Hong, 2010; Huang Rongying, 2010; Liao Min, 2013; Feng Keke, 2015). The community management and service specialty is an emerging one that conforms to the country's guidelines and policies, but its social identify is low. The public in our country generally lacks understanding of this specialty. Vocational students of community management and service in our college also have low identify and little interests or dissatisfied with this specialty. Therefore, it is necessary to analyze these issues.

\section{Literature Review}

By consulting relevant literature on specialty identity research in China, the research on specialty identity in China has drawn more and more attention from all walks of life. Searching for the keyword "specialty identity" in Wanfang database, the research trend of "specialty identity" from 2006 to 2017 is shown as follows:

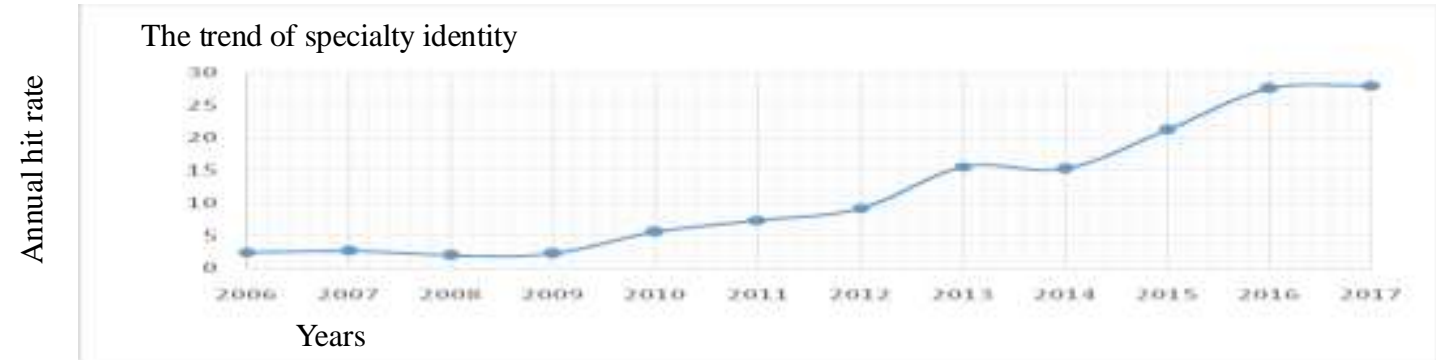

The connotation of specialty identity of college students is very extensive. Li Huimin (2008) believes in his research that specialty identity is the degree of identify of specialty which a student chooses, which is shown in the aspects of applying for the specialty, learning attitudes and employment attitudes. Liu Jianwen (2014) pointed out in the study that students' learning attitudes are determined by the degree of specialty identity. "Interests to a specialty play a very important role in the driving force of learning. Based on psychological theory, the best driving force for learning is the interests in the things we are learning." The community management and service 
specialty is a kind of social work specialty. Since the mid-1980s, China's social work education started slowly. Although significant progress has been made, the specialty identify of social work students is low without the enthusiasm for learning. Xi Hongqiang (2011) proceeded from the current situation of the social work specialty and conducted in-depth research on how to improve the specialty identity of social work students.

\section{Research Design}

This study designed a questionnaire for students of community management and service specialty, which mainly focused on specialty selection, specialty identify, learning situation, employment intentions and further study intentions, in order to find out their understanding, degree of satisfaction and identity of the specialty, to explore and analyze their views on this specialty, to analyze the relationship between their specialty selection and the understanding degree of the specialty, and the influence of specialty identification on learning. Questionnaires were distributed through WJX.CN to verify the contents. It was necessary to collect 11 copies of questionnaires of Class 1501 of Social Management and actually collected 11 copies. It was necessary to collect 15 copies of questionnaires of Class 1701 of Social Management and actually collected 17 copies. The total number of copies of questionnaires was 26.

\section{Research Result}

Specialty Selection. When it came to the problems of specialty selection before learning the courses of the specialty, all the students participating in the study had a relatively low specialty identify. From Figure 1, it can be seen that there were $34.62 \%$ out of the 26 students who participated in the study who did not understand this specialty before choosing it, and $65.38 \%$ only generally understood this specialty. Because the ways of the students of the two classes to enter the college were different. $90.91 \%$ of the students of Class 1501 of Social Management did not take this specialty as their first choice and the students of Class 1701 of Social Management is registered and $93.33 \%$ of them took this specialty as their first choice (Figure II).

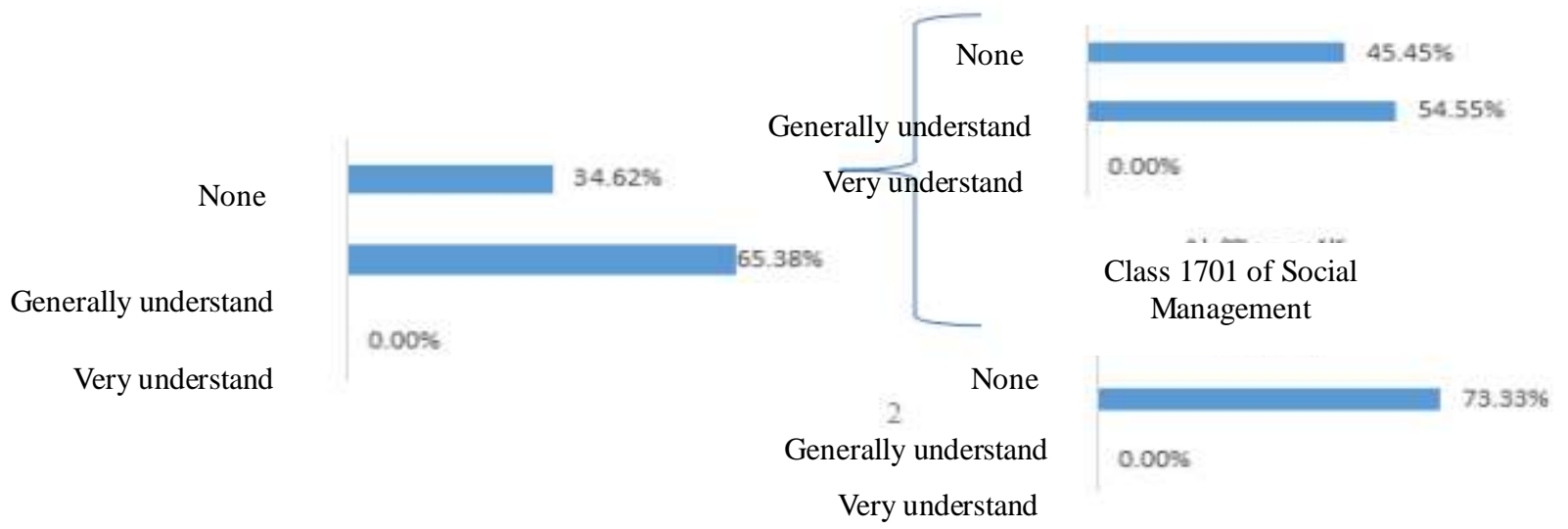

Fig 1 The understanding degree of Social Management before choosing the specialty 


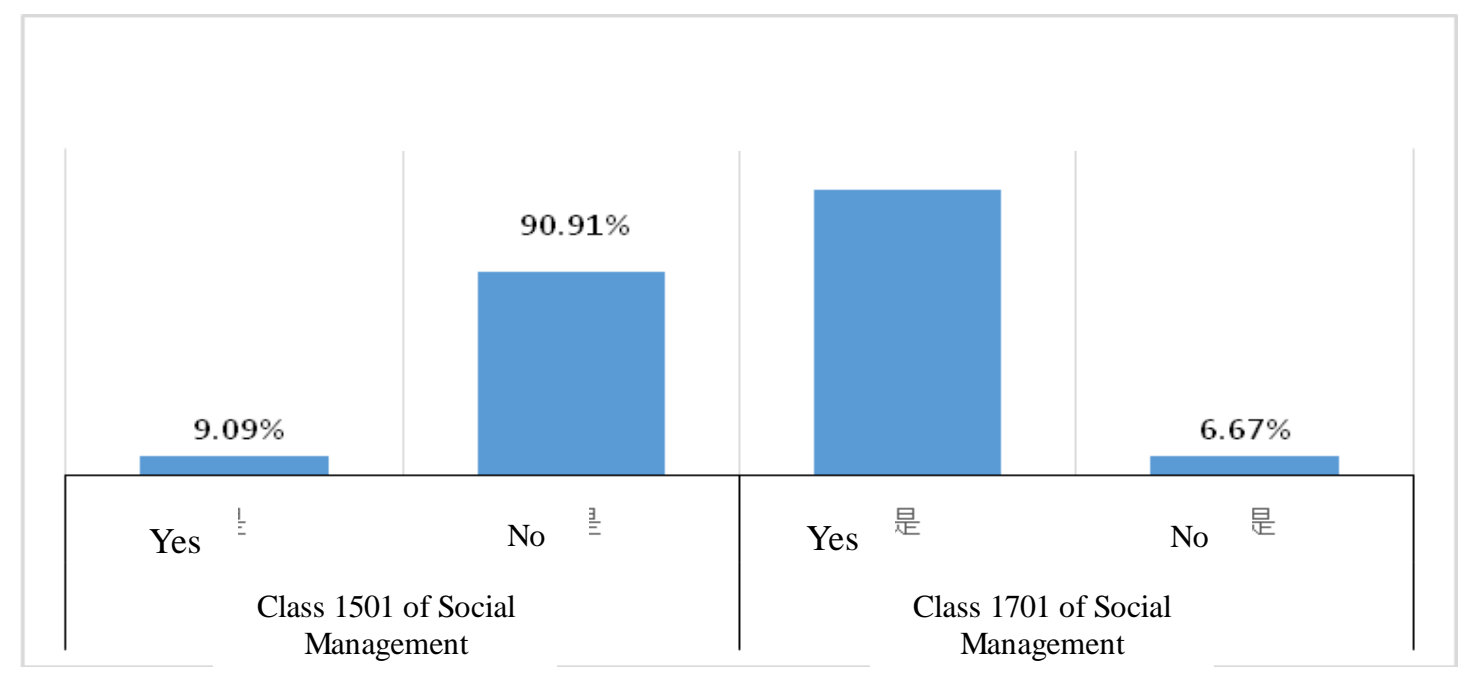

Fig 2 Is Social Management the first choice

Figure 3 and 4 show that $34.62 \%$ of the students chose this specialty according to their parents' wishes; $34.62 \%$ according to the guidance of others and only $30.76 \%$ according to their own wishes. Among them, $7.69 \%$ of the students chose this specialty rationally according to their interests and relevant information, which is a very good phenomenon; 50.00\% knew this specialty mainly through parents, teachers and friends and $26.92 \%$ actually did not understand this specialty and blindly applied for it. Blindness and conformity are not good attitudes, but this attitude and phenomenon is still filled with our lives and learning; of course, $15.39 \%$ who were assigned to this specialty because of obedience.

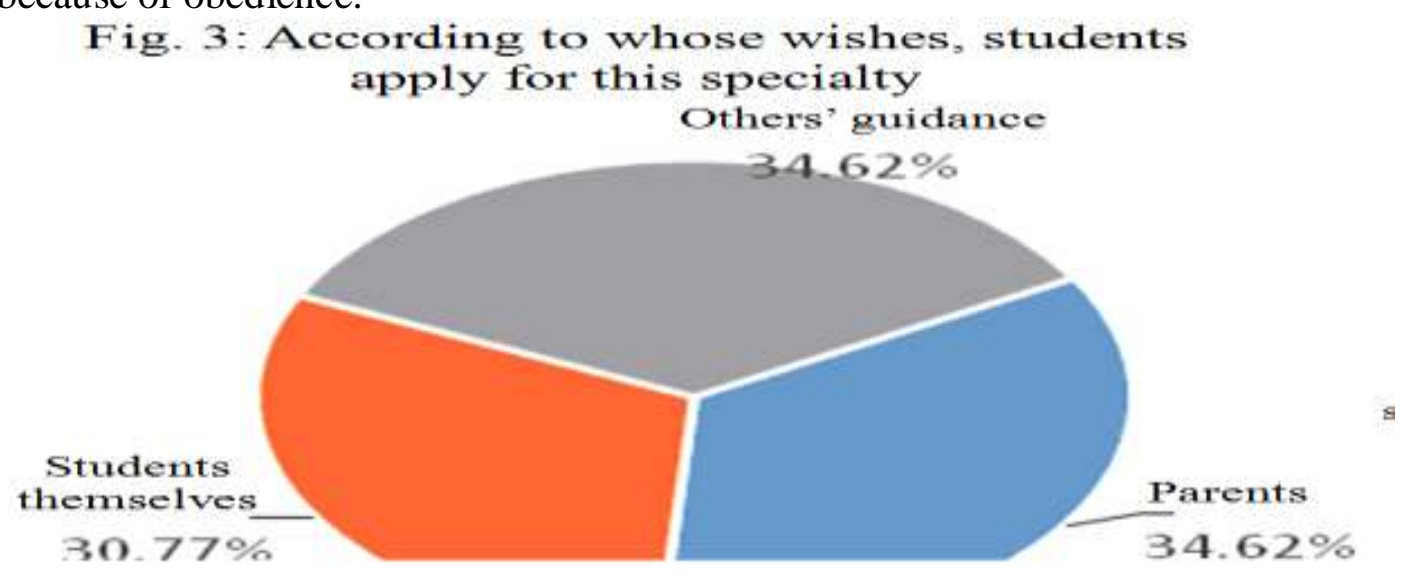

Fig 3 According to whose wishes, students apply for this specialty

Fig. 4: How do students know this specialty

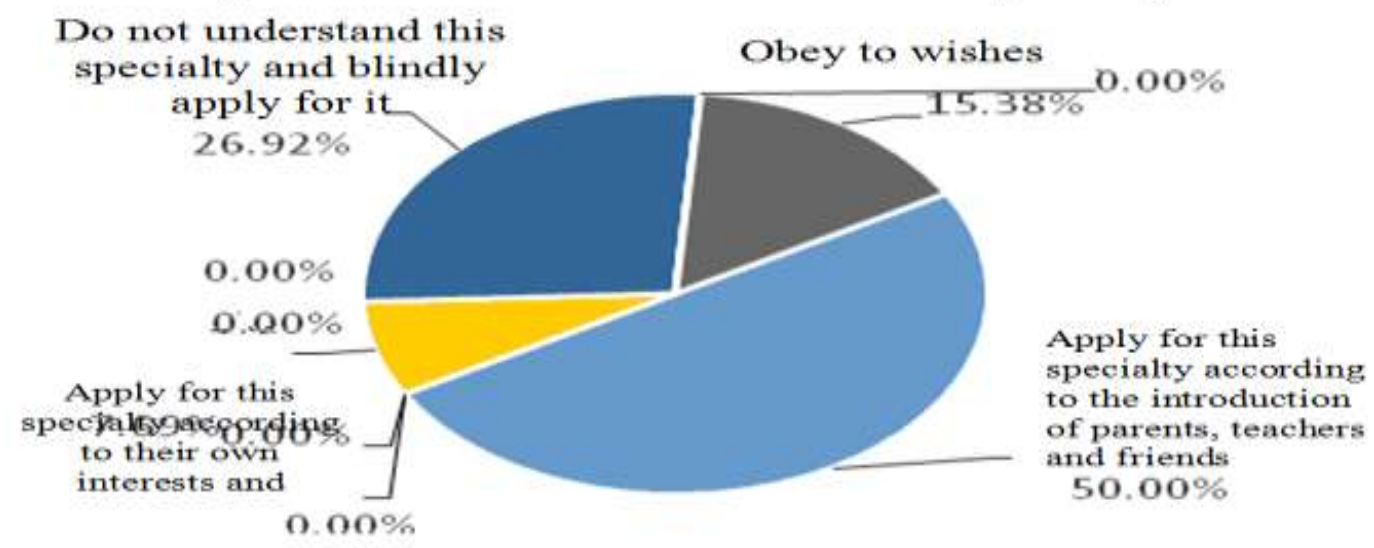


Learning Situation. By summing up the learning attitudes of the students of the two classes (Figure 5), 57.69\% of the students' learning attitudes were listening while playing in class. $7.69 \%$ did not take learning very seriously and just attended the class. $34.62 \%$ of the students were very correct in their attitudes towards learning and completed their assignments seriously. $53.33 \%$ of the students in Class 1701 of Social Management had more serious learning attitudes than that of Class 1501. Listening to teachers and taking notes in class were good attitudes towards learning, which is a good start for freshmen who just entered the college.

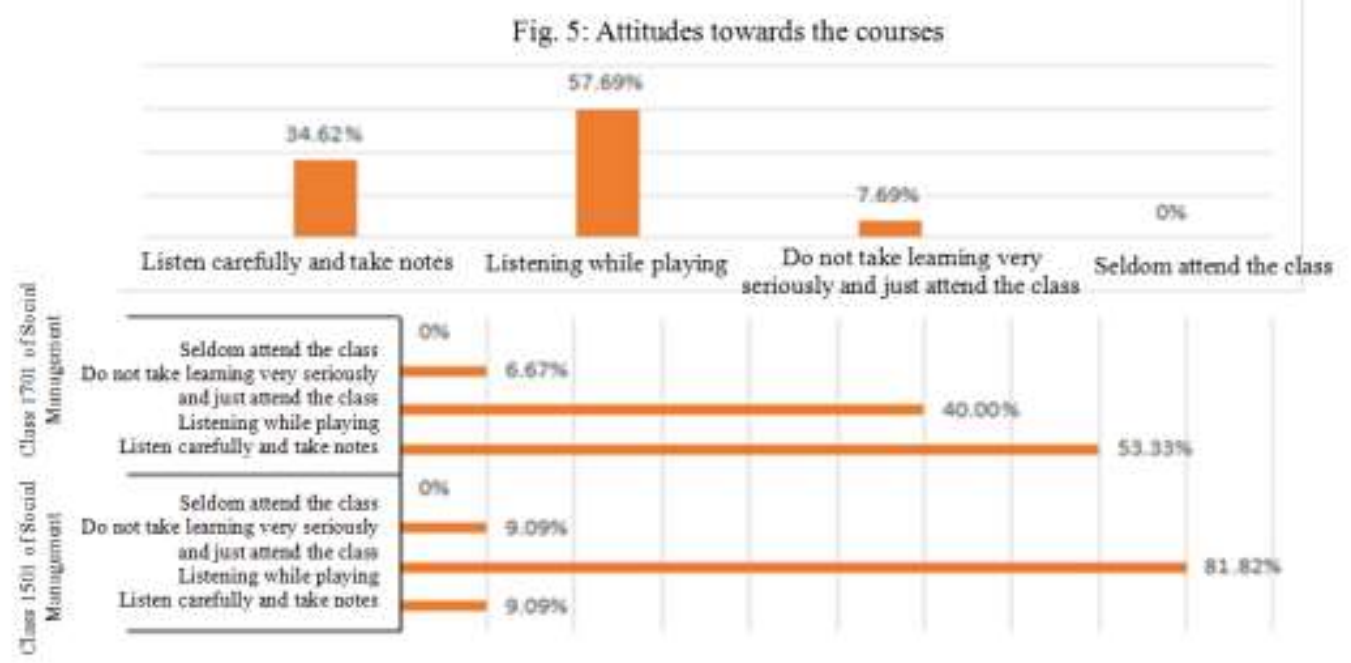

Fig.5.Attitudes towards the courses

The students in the two classes were also very different in the completion of homework and books recommended by teachers (Figure 6). In general, more than half of the 26 students of the study had bad attitudes towards homework. They thought that only finishing homework was enough. $3.85 \%$ of the students even did not do their homework, but $42.31 \%$ of them would conscientiously finish the homework assigned by teachers.

Fig. 6: The completion situation of the books recommended by teachers and the homework assigned by teachers

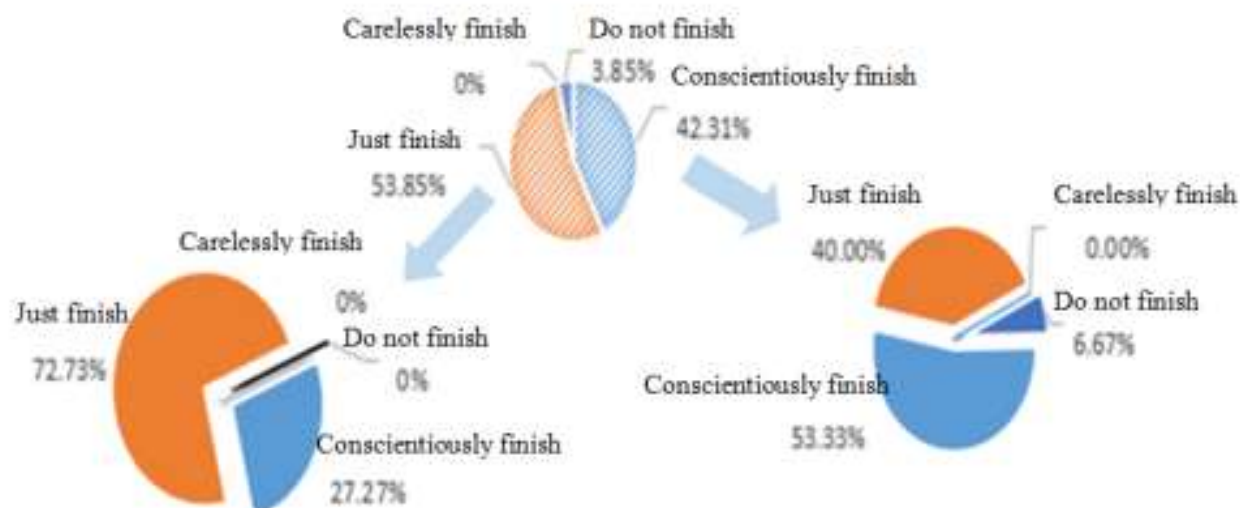

Fig 6 The completion situation of the books recommended by teachers and the homework assigned by teachers

Employment Intentions. Through the questionnaire, it can be seen that students' understanding of the employment direction of the specialty is shown in Figure $7.65 .38 \%$ of the students knew the specialty well and $34.62 \%$ had a general understanding of the specialty. In Social Management Class $1501,81.82 \%$ of the students knew the employment direction well and the good employment future of the specialty, but $72.73 \%$ of the students still thought the employment situation was not good and $27.27 \%$ considered this specialty to be not popular (Figure 8). 36.36\% of the students would be engaged in the related work of the specialty, $63.64 \%$ would not and most of the students 
did not have interests in the related work of the specialty (Figure 9). Students of Social Management Class 1701 had less understanding to the specialty than that of Social Management Class 1501. There were more than half of the students of Social Management Class 1701 who had a general understanding of the specialty and $46.67 \%$ of the students were in the general understanding stage. The social awareness of social management is not very high, and it is also a little understanding of it. Although $73.33 \%$ of the students thought that the employment situation of this specialty was general (Figure 8), 86.67\% of the students would be engaged in the related work (Figure 9) and were very interested in the related work of this specialty.

Fig. 7: The degree of understanding of the employment direction of this specialty

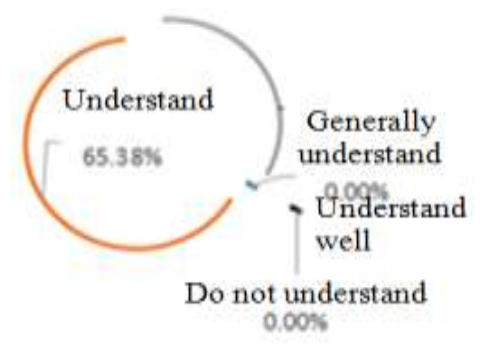

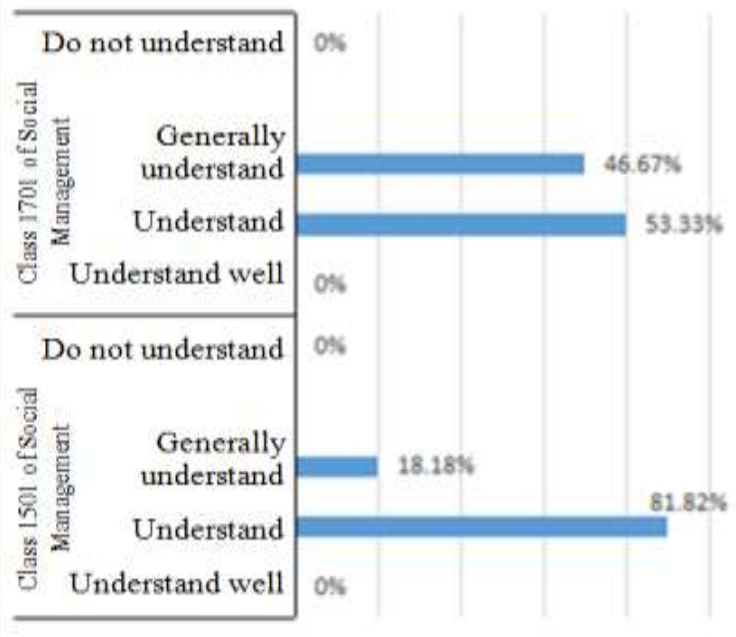

Fig 7 The degree of understanding of the employment direction of this specialty

Fig. 8: The employment future of this

specialty

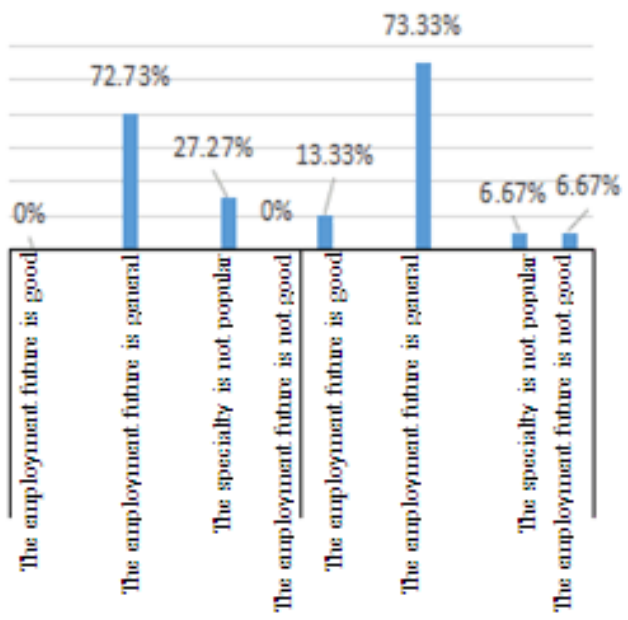

Fig. 9: Whether to be eng aged in the related work of this specialty

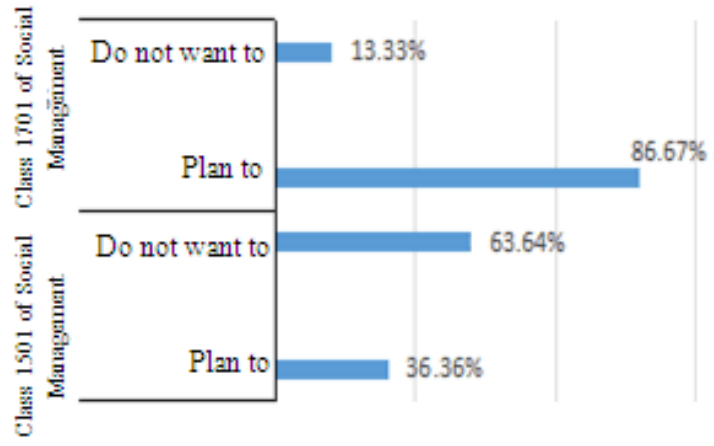

Further Learning Intentions. $80.77 \%$ of the students who participated in study had intentions to improve their academic qualifications. When asked if they would continue to choose Social Management, only $33.33 \%$ of them said they would continue and $66.67 \%$ of them said they would not continue to choose this specialty. Through "the comparison of whether to improve academic qualifications", it can be seen that most of the students in the two classes focused on the degree of education. For the students of the two classes who wanted to continue to improve their academic qualifications, "the comparison of whether they would continue to choose this specialty" also showed very different results. 
Fig. 10: Whether to improve academic qualifications

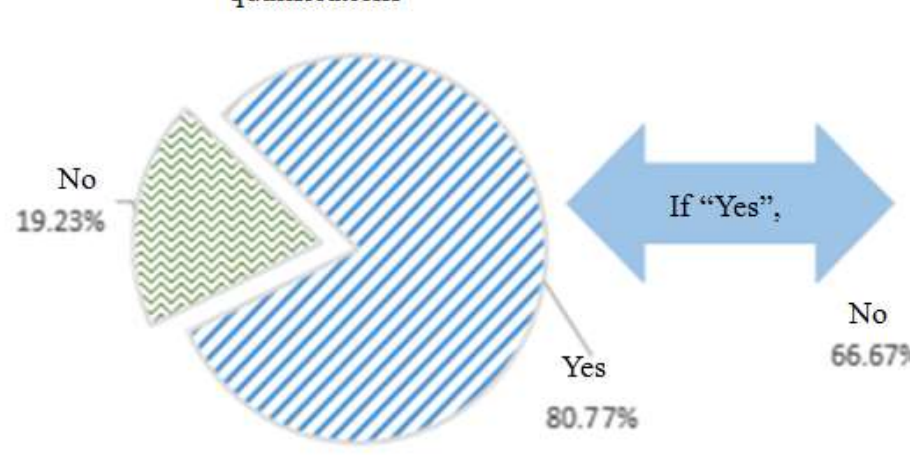

Fig. 11: Whether to continue to choose this specialty

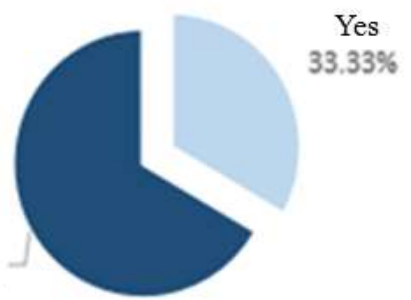

$90 \%$ of the students of Social Management Class 1501 said they would not choose this specialty. They had a gradual understanding of the specialty through the three years of study, but they were still not keen on it. Most of them were more interested in the qualification of teachers, and some were already prepare for the exam. 54.55\% of the students of Social Management Class 1701 said they would still choose this specialty and had more interests on this specialty than that of the students of Social Management Class 1501. In the interview, some of them chose this specialty because they were interested in teaching specialty which was the employment direction of Social Management. But due to different grades, teaching courses were different. The specialty direction for students of 1501 was education and for 1701 was community and property management. The students who were interested in the employment direction of preschool education would feel confused in learning.

Specialty Identify. It can be seen from Figure 12 that the specialty identify of all the students were not high. $34.62 \%$ of the students said they liked the specialty and $65.38 \%$ said they generally liked the specialty. According to the results of further learning intentions, the number of the students of Class 1701 who would still choose Social Management as the specialty for their further learning was obviously larger than that of Class 1501.

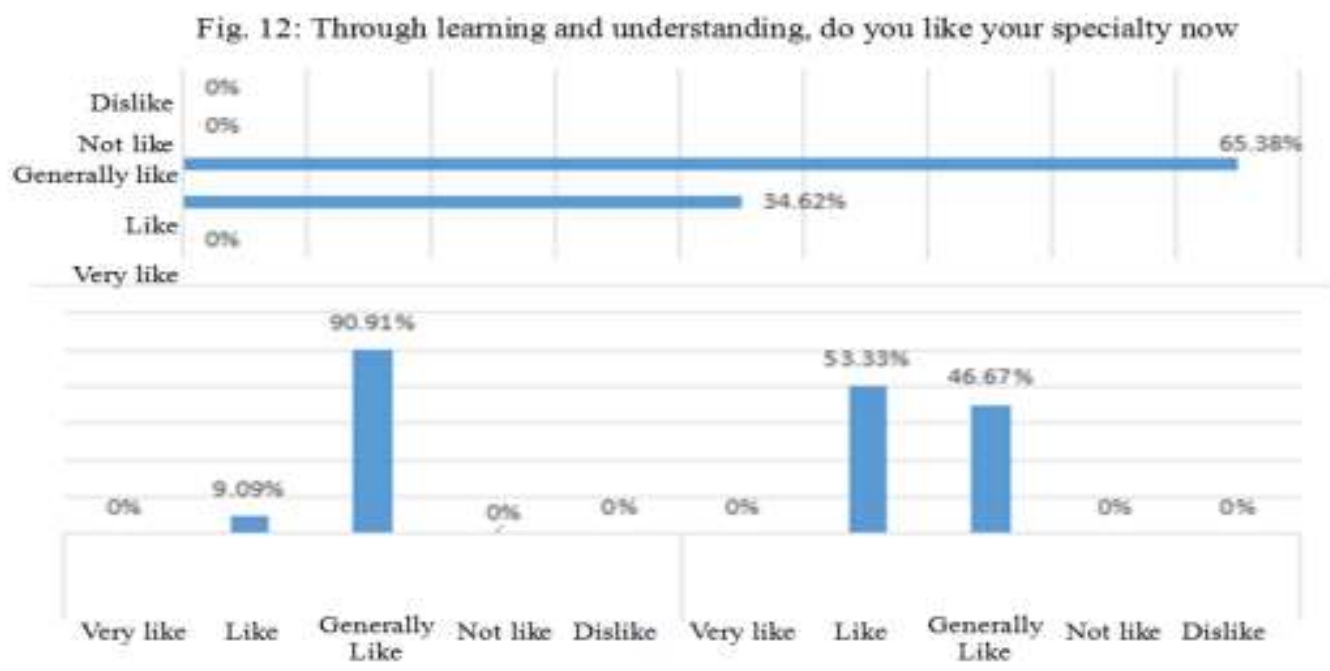

Fig 12 Through learning and understanding, do like your specialty now

\section{Strategies to Promote Specialty Identity}

In the study of the specialty identity of students in social management, Class 1501 of Social Management was a graduating class. The overall specialty identity of students was not high. Through three years of study, most of the student could pass the cultural courses, the deficiency was the combination of theory and practice was too little. Students of Class 1701 were freshmen and 
their specialty identity could be gradually cultivated. The follows are the author's suggestions from the learner's point of view.

Straighten out the State of Mind, Reasonably Position Planning. The best way for college students to choose social management is to have a clear career plan in the next three years based on their interests and hobbies. State of mind should be adjusted. It is possible to learn the specialty well although the specialty is not the first choice. To find out the value of self existence, when the value shows, the sense of identity will be shown. Establishing learning plan is a dynamic process, from which we can find out our own strengths and weaknesses, opportunities and challenges, which is helpful to position ourselves. When the small goals are achieved one by one, a sense of accomplishment will follow, which will change our thinking and mentality. Planning a good blueprint can make you have a clear understanding of this specialty and naturally give you a lot of satisfaction.

Avoid Blindly Follow and Rationally Choose Specialty. There are seldom students who have a whole understanding of the specialty they choose. For the students whose college entrance examination results are not ideal, they are less likely to understand or know the specialty they choose. The public's views of some specialties are too one-sided and subjective. The evaluations of a specialty are generally very good, not good or not popular. A large proportion of students choose specialties in accordance with popular psychology. At present, the market demand of social management specialty is very large, and there is a lot of room for development. Colleges and universities should do a good job in the characteristics publicity of each specialty to avoid the blind choice, so that students can reasonably choose their specialties and are familiar with their specialties, so as to improve specialty identity.

Expand Learning and Combine Theory with Practice. Different colleges may have different teaching plans of the same specialty. The school-enterprise cooperation of our college includes Longhu Real Estate, Property Association and cross-border e-commerce. The theoretical knowledge of social management is wide, and it involves all aspects of knowledge, but it is also accompanied by defects. Students cannot learn it very clearly. Although they have given more opportunities to choose the employment direction, each one needs to have the corresponding skills. The knowledge will be mixed. There are many employment directions of Social Management. According to teachers, the teaching plan to the students of Class 1701 is Property Management. Students with the intentions of teaching career can take the teacher qualification certificate exam according to their needs.

\section{Conclusion}

In this paper, the questionnaire is used to investigate part of the students of Social Management who entered the college in 2015 and 2017, so as to understand their views on this specialty and future employment intentions. Through the analysis of problems, the author puts forward some suggestions in the perspective of students. However, there are still problems in designing research questionnaires, because the number of students in this specialty is limited and the sample size is also small. As far as the current research trend, most of the research on social management specialty is to explore the management of practice teaching and is often concentrated in the medical field, followed by the education field. There are many aspects to be deeply explored in this specialty.

\section{Acknowledgements}

2017 Jiangsu Provincial Social Education Planning Topic "Study on the Construction Path and Effectiveness of Community Learning Community in Jiangsu Province" (Project Number: JSS-C-2017001); 2017 Jiangsu Philosophy and Social Science Research Project of Universities "Study on the Construction of Community Vocational Education and Training Mode on the Background of Two Cohesions, One High Level" (Project Number: 2017SJB0881); 2016 Wuxi Science and Technology Vocational College Science and Technology Fund Guide Project "Development and Application of English Listening and Speaking Teaching Software System Based 
on VR Mobile Technology" (Project Number: RJ1607).

\section{References}

[1] Yang Hong, Shi Yuancheng. Summary of Research on College Students' Specialty Identity[J]. China Electric Power Education, 2009 (10).

[2] Zhang Lili. Survey of Specialty Identity of the Students of Preschool Special Education[J]. Early Childhood Education·Education Science, 2008 (3).

[3] Wang Hong, Ma Tianfang. Empirical Analysis of the Development Prospect and Trend of Community Management and Service Specialty in Higher Vocational Colleges[J]. Education and Occupation, 2010 (2).

[4] Huang Rongying. On Practice Teaching Management of Community Management and Service Specialty[J]. Education and Occupation, 2011(6).

[5] Hu Xiaoai. Study of Factors and Adjustment Strategies of Specialty Identify of Vocational College Students[J]. Journal of Wuhan Polytechnic, 2011(10).

[6] Sun Yu. Multivariate Analysis and Strategy of Current Situation of Students' Specialty Identity Survey in Higher Vocational Colleges[J]. Journal of Wuxi Vocational and Technical College, 2016(1).

[7] Zhao Huiyong, Duan Peiyan, Jiang Xianglong. Application of Experiential Teaching in Specialty Identity Education in Higher Vocational Colleges[J]. Journal of Chengdu Teachers College, 2015(5).

[8] Xue Yanping. Exploration on the Reform of Talent Cultivation Model of Community Management and Service Specialty in Higher Vocational Colleges[J]. Journal of Jiangxi Youth Careers College, 2009,19(4).

[9] Di Weimin. Thinking on the Training Model of Community Specialty in Higher Vocational Colleges-Analysis of the Demands of Community Management and Service Specialty[J].Journal of Hebei Youth Administrative Cadre College, 2009(6).

[10] Li Jianling. Dilemma and Outlet: Exploration and Analysis of Specialty Development of Community Management and Service[J]. Journal of Henan Institute of Engineering (Social Science Edition), 2010, 25(4).

[11]Li Jianling. Problems and Countermeasures in Community Education and Service Education[J]. Heihe Journal, 2014(3). 